\title{
Expression of an Otx gene in the adult rudiment and the developing central nervous system in the vestibula larva of the sea urchin Holopneustes purpurescens
}

\author{
VALERIE B. MORRIS* ${ }^{*}$ JING-TING ZHAO\#, DEBORAH C.A. SHEARMAN, MARIA BYRNE ${ }^{1}$ and \\ MARIANNE FROMMER \\ Biological Sciences A12 and ' Anatomy and Histology F13, University of Sydney, NSW, Australia
}

\begin{abstract}
Expression of the Otx gene, HprOtx, from the sea urchin Holopneustes purpurescens, is described during the development of the adult echinoid rudiment in the vestibula larva of this species. The adult rudiment forms directly after gastrulation in the vestibula larva since, unlike the pluteus larva of most other sea urchin species, it is not a feeding larva. The expression is described during the period from hatching to a late vestibula larva. At hatching, HprOtx is expressed throughout the ectoderm of the gastrula. A short time later, expression is absent from the ectoderm on the oral side of the gastrula where the vestibule will form. In an early vestibula larva, HprOtx is not expressed in the ectodermal floor of the vestibule but is expressed in an asymmetric pattern in the aboral ectoderm. As the vestibule invaginates, HprOtx is newly expressed in the ectodermal floor of the vestibule as it develops into the neuroectoderm that is the anlage of the circum-oral central nervous system. The expression is at first in the central part of the floor, then it extends outwards to the ectoderm around the five primary podia and to the epineural folds between the podia. The epineural folds later close to form the radial nerves and the circum-oral nerve ring. In a late vestibula larva, HprOtx is expressed in the radial nerves and the nerve ring. The expression of an Otx gene in the developing echinoid central nervous system is interpreted as an instance of conserved gene expression in echinoderm development.
\end{abstract}

KEY WORDS: echinoderm, radial body plan, circum-oral nervous system, in situ hybridization, conserved gene expression

\section{Introduction}

The radial design of the echinoderm body plan is very different from the bilateral body plan of most other metazoans and as a consequence raises questions with respect to its evolutionary origin. That echinoderms evolved from a bilateral ancestor is generally accepted (Hyman, 1955; Lowe and Wray, 1997) but who the ancestor was and what the homologies are between the radial body plan and the bilateral body plan of the ancestor are unknown. In reporting the expression of the Otx gene here, it is relevant to decide whether the expression is indicative of a conserved function or whether it should be interpreted as a co-option of the gene to new uses. The idea of the co-option to new uses of the patterning genes shared with bilateral forms has been suggested as an explanation of the origin of the echinoderm radial body plan (Lowe and Wray, 1997; Davidson, 2001).
Otxgenes are orthologues of the Drosophilagene orthodenticle (otd) (Finkelstein et al., 1990) and were first identified in mouse (Simeone et al., 1992). Subsequently, in flies and mice, the otd/Otx genes were reported to have a conserved role in embryonic brain development (Hirth and Reichert, 1999). In particular, they specify the anterior brain regions in flies and mice, in contrast to the Hox genes which specify the posterior brain regions and the nerve cord (Hirth and Reichert, 1999; Arendt and Nübler-Jung, 1999).

Otx genes have also been identified widely in other species (Klein and Li, 1999). In sea urchins, Otxgenes have been characterized in Strongylocentrotus purpuratus (Li et al., 1997) and Hemicentrotus pulcherrimus (Kiyama et al., 1998). Two proteins, $\operatorname{SpOtx}(\alpha)$ and $\operatorname{SpOtx}(\beta)$, are generated from a single gene in $\mathcal{S}$. purpuratus (Li etal., 1997) and correspond respectively to the early

Abbreviations used in this paper: $\mathrm{Hpr}$, Holopneustes purpurescens.

*Address correspondence to: Dr Valerie B. Morris. Biological Sciences A12, University of Sydney, NSW 2006, Australia. Fax: +61-2-9351-4771. e-mail:valm@mail.usyd.edu.au

\# Current address: Victor Chang Cardiac Research Institute, St. Vincent's Hospital, 384 Victoria St., Darlinghurst, NSW 2010, Australia

$0214-6282 / 2004 / \$ 25.00$

(C) UBC Press

Printed in Spain

www.ijdb.ehu.es 
and late proteins, $\mathrm{HpOtx}_{\mathrm{E}}$ and $\mathrm{HpOtx}_{\mathrm{L}}$ in H. pulcherrimus, also generated from a single gene (Kiyama et al., 1998). The two forms of protein are identical in the homeodomains and $C$ terminal regions but differ in the $\mathrm{N}$ terminal regions. The $\mathrm{SpOtx}(\beta)$ form has similarities with the vertebrate Otx 1 and Otx2gene products ( $\mathrm{Li}$ et al., 1997). The cDNA sequence of the Otx gene we report for $H$. purpurescens, HprOtx, aligns with the cDNA of SpOtx( $\alpha)$ and

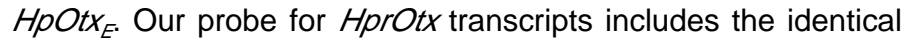
coding region and recognizes both possible transcripts.

We describe the expression of HprOtxin the vestibula larva of the sea urchin Holopneustes purpurescens. In this larva, the adult rudiment in which the adult sea urchin structures form begins development directly after gastrulation, reaching a pre-metamorphic juvenile sea urchin stage in about four days (Morris, 1995). This development is in contrast to that in most other sea urchin species which form a feeding larva, the pluteus, after gastrulation (Hyman,1955). In the pluteus, the adult rudiment begins development as a small structure rather like an imaginal disc on the side of the pluteus, taking several weeks to reach the juvenile sea urchin stage (Hyman, 1955). The adult rudiment in the $H$. purpurescens vestibula larva is large throughout its development by comparison, forming in a vestibule that occupies most of the larval body (Morris, 1995). Using this species, it has been possible to visualize the expression of HprOtxin the adult rudiment in whole-mount preparations of the larvae following in situ hybridization with a digoxigenin(DIG)-labelled probe. This method contrasts with that in a recent report of Otx expression in the vestibula larva of the sea urchin Heliocidaris erythrogramma where the expression in the adult rudiment was described from histological sections of larvae hybridized with a radio-labelled probe (Nielsen et al., 2003). Our images of the whole-mount preparations in different orientations give an integrated picture of the three-dimensional expression patterns of HprOtxin the larvae, particularly during the morphogenesis of the adult echinoid central nervous system.

\section{Results}

Two genomic fragments and a cDNA fragment of the Otxgene, HprOtx, were cloned from $H$. purpurescens. The amino acid conceptual translation of these HprOtxfragments is aligned in Fig. 1 with the amino acid sequences of the complete coding regions of SpOtx( $\alpha$ )(Gan et al., 1995; Li et al., 1997) and HpOtx (Sakamoto et al., 1997). The alignment is divided into two regions: an $\mathrm{N}$ terminal region which characterizes the $\alpha$ protein isoform of SpOtx and the $\mathrm{E}$ protein isoform of $\mathrm{HpOtx}$, then a $\mathrm{C}$ terminal region which is common to both the $\alpha$ and $\beta$ isoforms of SpOtx (Li et al., 1997) and the $E$ and $L$ isoforms of HpOtx (Sakamoto et al., 1997). This common $\mathrm{C}$ terminal region includes the homeodomain. The alignment of the HprOtx sequence in the $\mathrm{N}$ terminal region indicates identity with the $\operatorname{SpOtx}(\alpha)$ and $\mathrm{HpOtx}_{E}$ isoforms. There are, however, amino acid substitutions, small insertions and deletions and two substantial insertions in the HprOtx sequence in this region. In the common $\mathrm{C}$ terminal region, there is high sequence identity between HprOtx, $\operatorname{SpOtx}(\alpha)$ and $\mathrm{HpOtx}_{\mathrm{E}}$ and the homeodomains are identical. The region from which the in situhybridization probe was constructed (Fig. 1) comprises mainly the common region and would be expected to bind to either of the two forms of transcript. Even so, using forward primers specific for the $\mathrm{N}$ terminal region of HprOtx (Fig. 1) we showed in an RT-PCR experiment that the HprOtx transcript was present from hatching up to late vestibula larval stages.

The expression of HprOtx in H. purpurescens larvae is described from in situ hybridizations using a DIG-labelled antisense RNA probe during the period from hatching up to a late vestibula larva. In control in situ hybridizations, a DIG-labelled sense RNA probe was used.

HprOtxis expressed throughout the ectoderm of the gastrula at hatching (Fig. 2A). A short time after hatching, when the gastrula is rounded and as long as it is broad, the expression is no longer

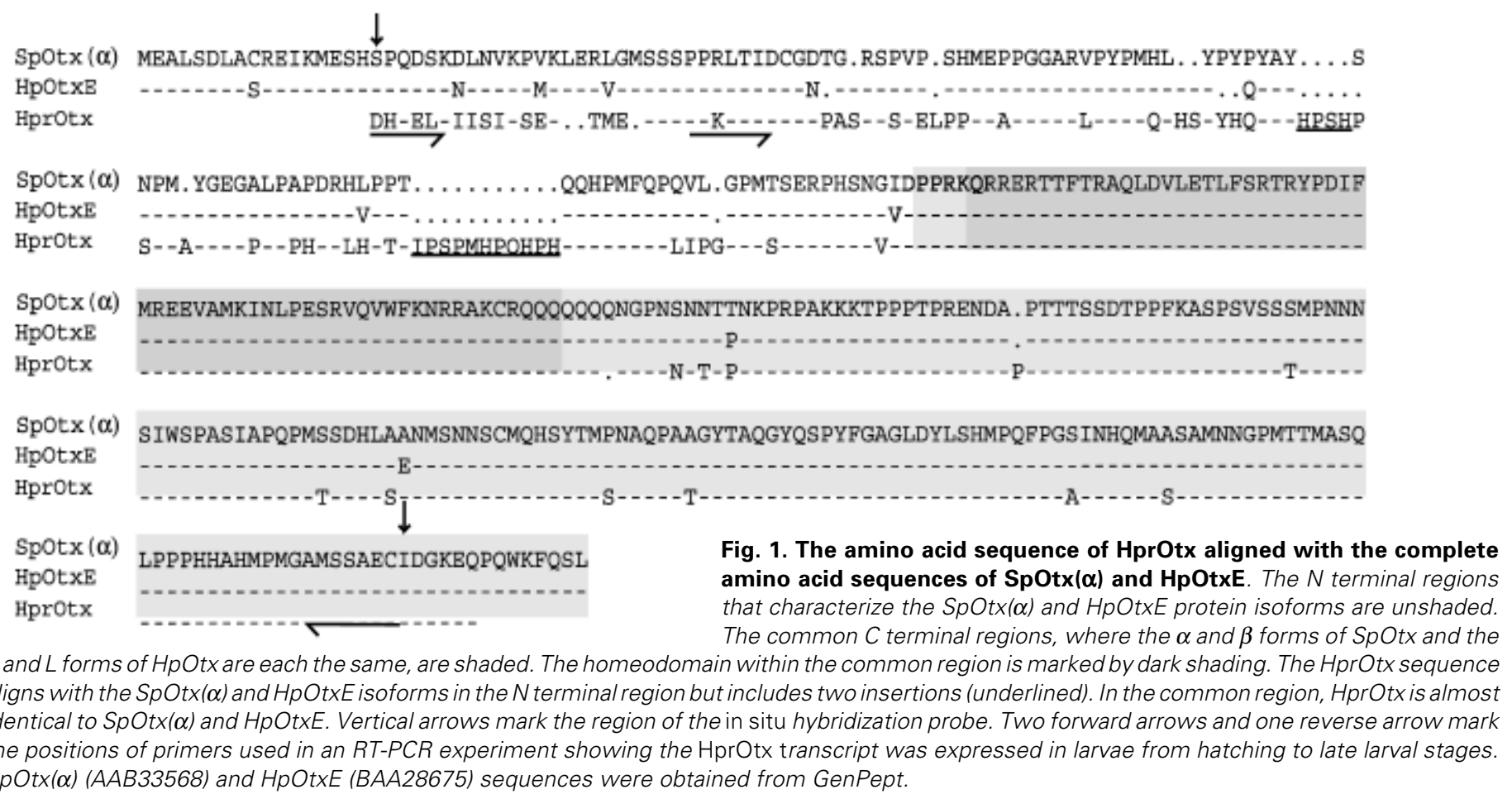



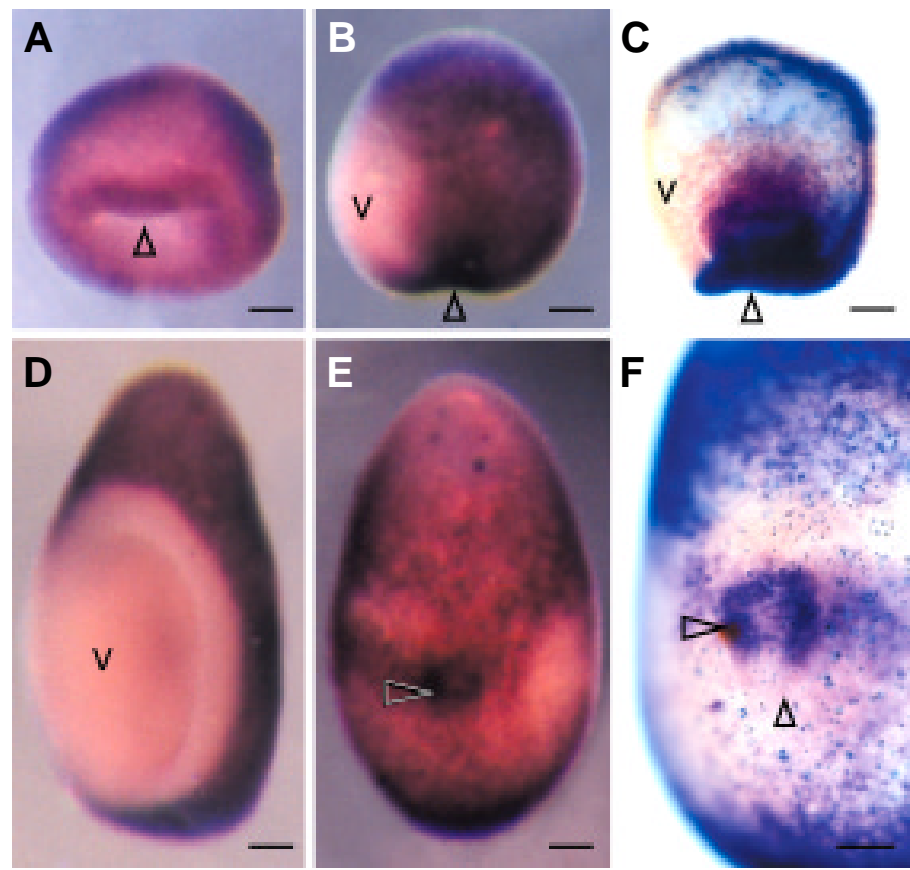

Fig. 2. HprOtx expression in gastrulae $(A, B, C)$ and early vestibula larvae (D,E,F). $A, B, D, E$ in aqueous media; $C, F$, cleared specimens. Arrows mark the blastopore in $A, B, C$. (A) Oblique vegetal view, the expression is throughout the ectoderm; 15 hours after fertilization (h). (B,C) Lateral views, oral left, showing lack of expression in the vestibule anlage (v). (C) is an optical section. (B) $19 \mathrm{~h}$; (C) $17 \mathrm{~h}$. Vegetal pole down in D to F. (D) Oral view showing lack of expression in the vestibule ( $\mathrm{V}$ ) and around its margin; $33 \mathrm{~h}$. (E) Aboral view, an asymmetric expression pattern in the ectoderm (see text) and expression in the aboral coelom (arrow); 33 h. (F) Optical section, aboral view, showing expression in the head of the aboral coelom (large arrow) and no expression in the fundus (small arrow); $34 \mathrm{~h}$. Scale bar, $50 \mu \mathrm{m}$.

detected in the ectoderm of the vestibule anlage on the adult oral side of the gastrula (Fig. 2 B,C). Several hours later, when the gastrula has elongated and invagination of the vestibule has begun, there is no HprOtxexpression in the vestibule ectoderm or in a band around the margin of the vestibule (Fig. 2D). Aborally at this stage, on the side opposite the vestibule, HprOtx expression is extensive but not uniform. There are two zones of lesser HprOtx expression, transverse with respect to the long larval axis, with a dark band of expression between them (Fig. 2E). The dark band, however, does not extend across all the aboral ectoderm. On the right in aboral view, there is a distinct patch of lesser HprOtx expression (Fig. 2E). Thus, HprOtx expression in the aboral ectoderm is asymmetric. Internally in the vestibula larva, HprOtx expression is intense at the head of the aboral coelom and this is visible in the stereomicroscope images in aqueous media (Fig. 2E) and in the cleared specimens (Fig. 2F). The HprOtx expression is absent from the fundus of the aboral coelom (Fig. 2F). The aboral coelom in the vestibula larva is the same structure as the right coelom in the pluteus.

The expression of HprOtx in the central nervous system as it develops in early to late vestibula larvae is shown in Figs. 3, 5 and 6 . Figure 4 shows control in situhybridizations where the absence of a colour reaction indicates that the sense probe transcribed from the HprOtx sequence has failed to bind mRNA. The first expression in the nervous system is the expression that newly appears in the ectoderm of the vestibule floor, as invagination of the vestibule progresses (Fig. 3A). The expression is in the central vestibule floor partly overlying the medial portions of the mesodermal pouches of the hydrocoele that form the primary podia (Fig. 3B). Two pairs of these podia lie astride the midline of the larva with a fifth podium on the midline (Fig. 3 B,D). In its early stages, the HprOtx expression is most intense in the ectoderm overlying the first and second pairs of podia (Fig. 3B). As the podial buds develop, the HprOtx expression is distinct in the ectoderm overlying the medial portions of all primary podia (Fig. $3 \mathrm{C}, \mathrm{D}$ ). The mouth anlage is central with respect to these primary podia.

Later in nervous system development, HprOtx expression has spread outwards in the ectoderm around the primary podia finally encircling each podium (Fig. $5 \mathrm{~A}, \mathrm{~B}$ ). This expression is in the ectoderm around the bases of the podia and does not reach the podial termini (Fig. 5C). Between the primary podia are the five epineural folds. HprOtxis expressed throughout these folds at this stage (Fig. 5 B,C). The expression in the folds is continuous with
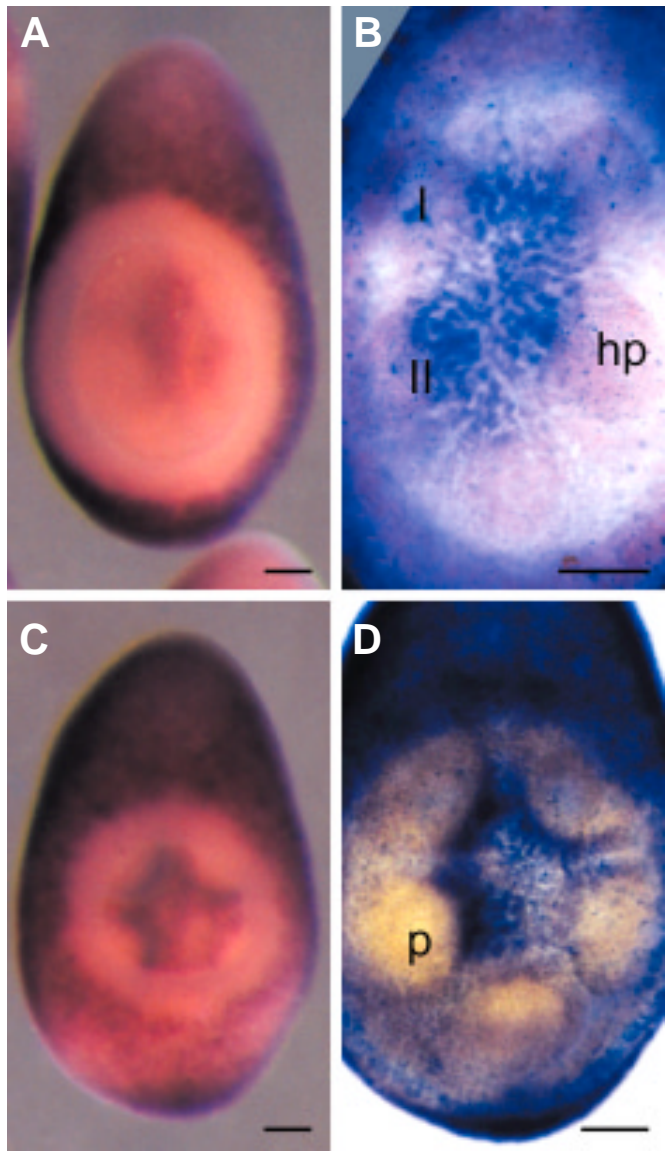

Fig. 3. HprOtx expression in the ectodermal floor of the vestibule in vestibula larvae. Vegetal pole down. $(A, C)$ In aqueous media; $(B, D)$ cleared specimens. (A) Oral view, showing early expression in the central vestibule floor. (B) Optical section, aboral view, showing expression in the medial regions over the hydrocoele pouches (hp) mostly over the first (I) and second (II) pairs of pouches. (C,D) Oral views showing later expression in the medial ectoderm of nascent primary podia (p). (D) An optical section. $(A, B, C, D) 37 \mathrm{~h}$. $(A, C)$ and $(B, D)$ illustrate the range of developmental stages which is often present at any one age. Scale bar, $50 \mu \mathrm{m}$. 

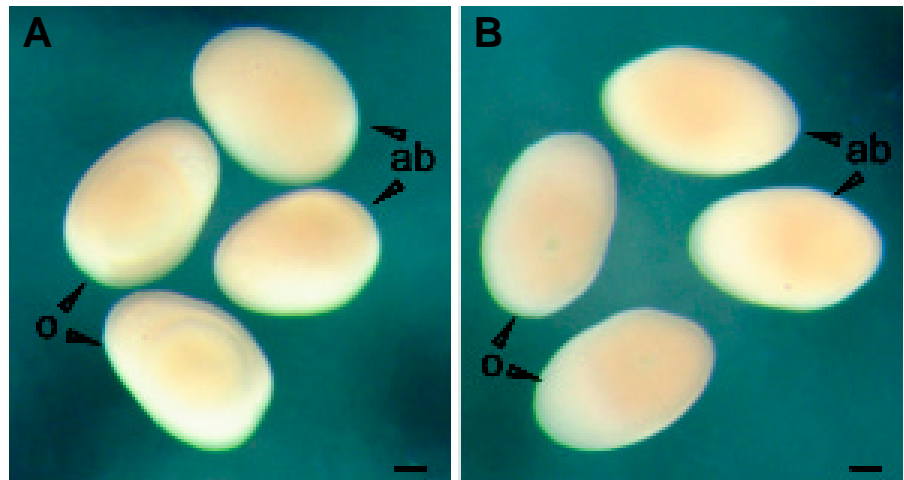

Fig. 4. Vestibula larvae from control in situ hybridizations. The mRNA in situ hybridizations were done with the sense (control) probe (see Materials and Methods). (A,B) Four larvae, two in oral view (o) and two in aboral view (ab) photographed in aqueous medium with epi-illumination. No colour reaction is evident, indicating that the sense DIG-labelled probe has not bound. (A) $39 \mathrm{~h}$; (B) $45 \mathrm{~h}$. Scale bar, $100 \mu \mathrm{m}$.

the expression in the epithelium of the central vestibule floor (Fig. $5 \mathrm{~B}, \mathrm{C}$ ) at whose outer edges the folds arise (Fig. 5 B,C).

The later growth of the epineural folds centrally and their fusion over the bases of the primary podia and between the primary podia is an important morphogenetic movement in the development of the echinoid central nervous system. One side of an epineural fold fuses with the side of a neighbouring fold over the medial base of a primary podium forming the radial nerve (Fig. 6 $A, B)$. HprOtx is expressed in the epithelium of the radial nerve (Fig. 6B). The leading edges of each epineural fold between the primary podia complete the coverage of the circum-oral nerve ring. HprOtxis expressed in the epineural folds between the podia (Fig. 6A). The epineural folds are entirely ectodermal (von Ubisch, 1913). The mesodermal tooth sacs between the five arms of the
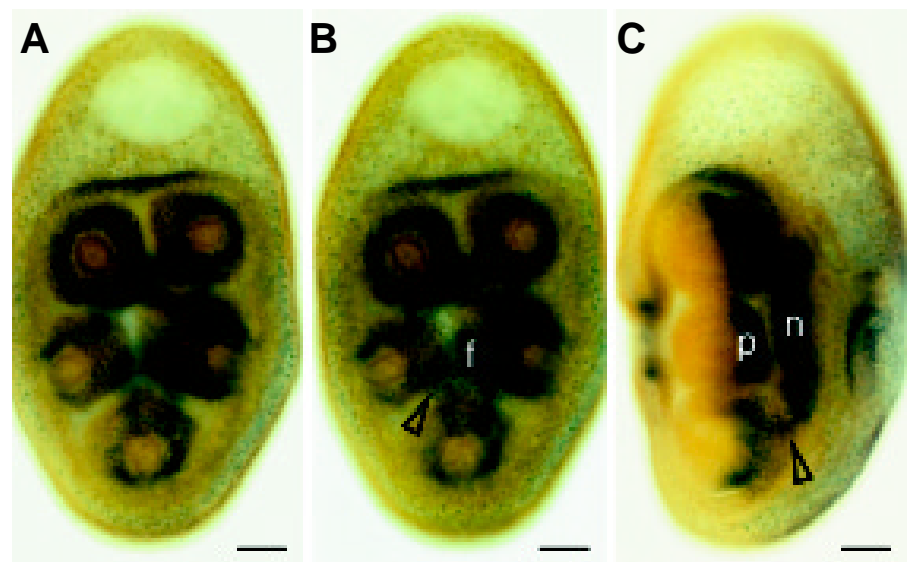

Fig. 5. HprOtx expression in a vestibula larva at an early epineural fold stage. Cleared specimen, vegetal pole down. $(A, B)$ Optical sections, aboral views. The focus in $(\mathbf{A})$ is on expression in the ectoderm around the five primary podia. In (B), the focus is at a more aboral level than in (A) showing expression in the vestibule floor ( $f$ ) and the epineural folds (arrow) between the podia. (C) Optical section of the same specimen in lateral view showing expression in the neuroepithelium (n) of the vestibule floor, the epineural folds (arrow) and around the bases of the podia (p). (A, B, C) $51 \mathrm{~h}$. Scale bar, $50 \mu \mathrm{m}$. hydrocoele lie under the epineural folds at early stages of development, not within them (von Ubisch, 1913). In our observations, the mesodermal tooth sacs between the hydrocoele arms are, in optical sections, aboral to the epineural folds (not shown). At a late stage of rudiment formation, HprOtx is expressed only in the nerve ring and proximal radial nerves (Fig. 6B).

\section{Discussion}

Expression of the Otx gene in the vestibula larva of $\mathrm{H}$. purpurescens has some parallels with Otx expression in other species. The early expression of the Otx gene throughout the ectoderm of the newly hatched larva is similar to the expression of the late form of the Otxgene in the ectoderm of gastrulae of the sea urchin Heterocentrotus pulcherrimus (Mitsunaga-Nakatsubo et al., 1998), as well as perhaps to the expression of Otx2 throughout the early mouse epiblast (Hirth and Reichert, 1999). The subsequent down-regulation of the Otxgene in the ectoderm of the vestibule of the $H$. purpurescens larva is similar to that described in another non-feeding larva, from the holothurian class of echinoderms (Lowe et al., 2002). The dark band of expression in the aboral ectoderm of the $H$. purpurescens larva has some resemblance to the Otx expression in the ciliated bands of this same holothurian larva, although the ectoderm is uniformly ciliated in the $H$. purpurescens larva (Morris, 1995). With respect to expression in the nervous system, expression has been reported in the vestibula larva of Heliocidaris erythrogramma at the future site of the radial nerve and in the nerve ring (Nielsen et al., 2003).

Our results from the whole-mount in situ hybridizations show that the Otxgene is expressed throughout the development of the central nervous system in the vestibula larva of $H$. purpurescens. The expression is first evident in the ectodermal floor of the vestibule, starting centrally in this ectoderm, then spreading outwards to the medial and outer faces of the developing primary podia and the epineural folds. The Otx gene continues to be expressed in the radial nerves and nerve ring after fusion of the epineural folds completes the development of the circum-oral nerve ring.

This expression of an Otx gene in the central nervous system of an echinoderm can be likened to the expression of the otd/Otx genes in the central nervous systems of flies and mice. In flies and mice, the suggestion of an evolutionary conserved role of the otd/ Otx genes in anterior embryonic brain development is based on similar expression patterns in the anterior brain regions (Hirth and Reichert, 1999) and on experiments that show these genes share conserved genetic functions (Acampora et al., 1998). To suppose that the expression we report of an Otx gene in central nervous system development in an echinoderm should also be considered to point to a conserved role might be justified if there were structural homology between the central nervous system of echinoderms and the anterior brain regions of flies and mice. Such homology is to a degree supported by evidence that the mouth in echinoderms is at the anterior end of the anteriorposterior axis of the postulated bilateral echinoderm ancestor (Peterson et al., 2000).

The central nervous system of an echinoderm is unusual in that it has radial symmetry consisting of a circum-oral nerve ring and five radial nerves connecting with the nerve ring (Hyman, 1955). The tissue of which it is composed, however, and the 

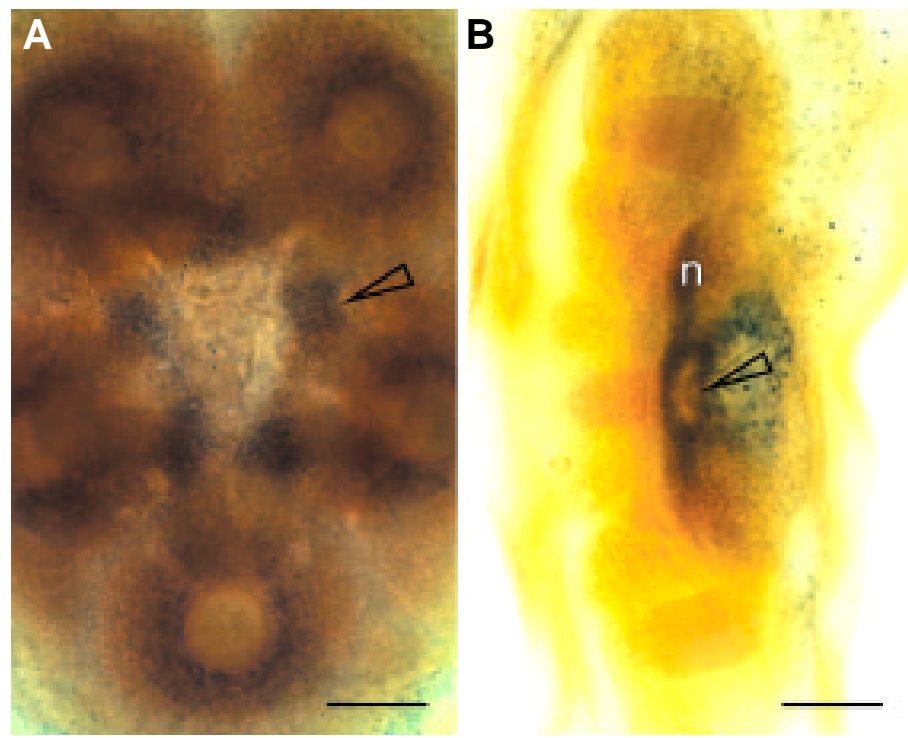

Fig. 6. HprOtx expression in late vestibula larvae. Cleared specimens, vegetal pole down. (A) Optical section, oral view. Expression is in the leading (medial) edges of the epineural folds (arrow) between the podia. Some expression still remains in the ectoderm of the five primary podia; $79 \mathrm{~h}$. (B) Optical section in lateral view, oral left. Expression is in the radial nerve (arrow) and the epithelial roof of the radial nerve, and the nerve ring (n); 95 $h$. Expression was also detected in cells in the ring canal, to the right of the radial nerve in the figure. Scale bar, $50 \mu \mathrm{m}$.

manner in which it folds in sea urchins has similarities with the neural tube of vertebrates (Heinzeller and Welsch, 1999). Homology between the central nervous system of an echinoderm and the anterior central nervous systems of other metazoans was argued for previously (Morris, 2001) on the basis of the circum-oral character of the echinoderm nervous system. An anterior circum-oral nervous system is a character of protostomes, a supraphyletic group that includes the phylum to which flies belong as well as most of the other metazoan phyla excepting chordates. In flies, the anterior nervous system consists of the supraoesophageal ganglia and suboesophageal ganglia that encircle the mouth. The anterior nervous system of chordates is not circum-oral, however, and for it to be homologous with the circum-oral anterior nervous system of protostomes, requires a closure of the mouth opening in the anterior brain region as proposed (Arendt and Nübler-Jung, 1994, 1997) and an inversion of the chordate dorsoventral axis (Arendt and Nübler-Jung, 1994, 1997, 1999; De Robertis and Sasai, 1996; Nielsen, 1999). The echinoderm nervous system becomes homologous with these other metazoan nervous systems when it is assumed that its circum-oral nervous system is homologous with the circum-oral anterior nervous system of protostomes. On this assumption, we conclude that the expression of the Otx gene in the echinoderm nervous system is conserved and comparable with the expression of otd/Otx in flies and mice.

Our conclusion implies that conserved gene function has a role in body plan patterning in echinoderms as it does in bilateral metazoans and links echinoderms with other groups with respect to the ways that genes might act in development. Other reports of expression data of common body plan patterning genes in echi-

noderm development have mostly interpreted the expression patterns as a co-option of genes to new uses and the divergent radial body plan of echinoderms has been attributed to the recruitment of some conserved genes to new uses (Davidson, 2001; Lowe et al., 2002). Our interpretation of Otx expression, however, is of a conserved gene function in central nervous system development.

\section{Materials and Methods}

\section{Isolation of HprOtx cDNA}

Two HprOtx gene fragments were isolated from genomic DNA of $H$. purpurescens using two pairs of primers with degeneracy. The primers were designed from SpOtx (Gan et al., 1995) and HpOtx (Sakamoto et al., 1997) sequences, and an HtOtx sequence from Heliocidaris tuberculata (Nielsen et al., 2003).

The first primer pair, primer A (5'-TCGTGWAATCAAGATGGAATCACAT-3') and primer $B$ ( $5^{\prime}$-CGAATGCGGCCTTTCACTGG-3'), isolated a fragment in the coding region $5^{\prime}$ of the homeobox. The second primer pair, primer C (5'-AATAGGAGAGCRAAGTGYAGGC-3') and primer D (5'-GACTGGAACTTCCATTGCGG-3'), isolated a fragment in the coding region that included the $5^{\prime}$ end of the homeobox and ended just $5^{\prime}$ of the termination codon.

From the sequences of these two fragments, two gene specific primers, primer E (5'-GGGATCACCAGGAGCTCAAG-3'), immediately $3^{\prime}$ of primer $A$ and primer $F$ (5'-CTATGTAAGACGTGAGCTGTAAC-3'), immediately $5^{\prime}$ of primer $D$, were designed to amplify a single fragment from cDNA from $H$. purpurescens, prepared as described (Morris et al., 2002). The single fragment, HprOtx, was characterized (GenBank accession no. AY278119).

\section{RNA probe preparation}

Probe template DNA for an in vitrotranscription labelling reaction was amplified from a cloned HprOtx fragment using two gene specific primers, one with a T7 RNA polymerase binding site at the $5^{\prime}$ end. For the antisense probe template, the T7 binding site was on the reverse strand primer and for the sense (control) probe template, the T7 binding site was on the forward strand primer. The probe template was purified by extraction from an agarose gel and concentrated by ethanol precipitation. The probe template of $1 \mathrm{~kb}$ was used in an in vitrotranscription reaction, labelling the product with DIG-11-UTP (Roche) using a MEGAscript ${ }^{\mathrm{TM}}$ T7 kit (Ambion) according to the manufacturer's instructions. The RNA product was purified by precipitation in $5 \mathrm{M} \mathrm{NH}_{4}$-acetate before use in the hybridization reactions.

\section{Fixation of larvae and in situ hybridization}

H. purpurescens larvae, cultured as previously described (Morris, $1995)$, were fixed in $4 \%(w / v)$ paraformaldehyde in RNAase-free sea water for $2 \mathrm{~h}$. They were then processed for mRNA in situhybridization of whole-mounts following the procedure of Davidson et al. (1999) except that the RNA probes were synthesized as described above. The alkaline phosphate conjugated DIG-labelled probe was detected with the NBTBCIP colour detection system (Roche).

\section{Observations}

After in situ hybridization, larvae were photographed in aqueous media through a stereomicroscope with epi-illumination, or they were dehydrated in a series of ethanols, cleared in 2:1 (v/v) benzyl benzoate and benzyl alcohol and photographed in a Zeiss Axiophot microscope with transmitted illumination.

\section{Acknowledgements}

We thank K. Steiner for instruction on whole-mount in situ hybridization, H. Sowden for collecting sea urchins and M. Ricketts for advice on 
photography. We thank M. Nielsen for providing HtOtx sequences before publication. The work was supported by the Australian Research Council Large Grant Scheme.

\section{References}

ACAMPORA, D., AVANTAGGIATO, V., TUORTO, F., BARONE, P., REICHERT, H., FINKELSTEIN, R. and SIMEONE, A. (1998). Murine Otx1 and Drosophila otd genes share conserved genetic functions required in invertebrate and vertebrate brain development. Development 125: 1691-1702.

ARENDT, D. and NÜBLER-JUNG, K. (1994). Inversion of dorsoventral axis? Nature 371: 26.

ARENDT, D. and NÜBLER-JUNG, K. (1997). Dorsal or ventral: similarities in fate maps and gastrulation patterns in annelids, arthropods and chordates. Mech. Dev. 61: 7-21.

ARENDT, D. and NÜBLER-JUNG, K. (1999). Comparison of early nerve cord development in insects and vertebrates. Development 126: 2309-2325.

DAVIDSON, B.P., KINDER, S.J., STEINER, K., SCHOENWOLF, G.C. and TAM, P.P.L. (1999). Impact of node ablation on the morphogenesis of the body axis and the lateral asymmetry of the mouse embryo during early organogenesis. Dev. Biol. 211: 11-26.

DAVIDSON, E.H. (2001). Genomic Regulatory Systems. Academic Press, San Diego.

DE ROBERTIS, E.M. and SASAI, Y. (1996). A common plan for dorsoventral patterning in Bilateria. Nature 380: 37-40.

FINKELSTEIN, R., SMOUSE, D., CAPACI, T.M., SPRADLING, A.C. and PERRIMON, N. (1990). The orthodenticlegene encodes a novel homeodomain protein involved in the development of the Drosophila nervous system and ocellar visual structures. Genes Dev. 4: 1516-1527.

GAN, L., MAO, C.-A., WIKRAMANAYAKE, A., ANGERER, L.M., ANGERER, R.C. and KLEIN, W.H. (1995). An orthodenticle-related protein from Strongylocentrotus purpuratus. Dev. Biol. 167: 517-528.

HEINZELLER, TH. and WELSCH, U. (1999). The complex of notochord/neural plate in chordates and the complex of hydrocoel/ectoneural cord in echinoderms - analogous or homologous? In C. Carnevali and Bonasoro (eds) Echinoderm Research 1998. Balkema, Rotterdam, 285-290.

HIRTH, F. and REICHERT, H. (1999). Conserved genetic programs in insect and mammalian brain development. BioEssays 21: 677-684.

HYMAN, L.B. (1955). The Invertebrates: Echinodermata. McGraw-Hill, New York.

KIYAMA, T., AKASAKA, K., TAKATA, K., MITSUNAGA-NAKATSUBO, M., SAKAMOTO, N. and SHIMADA, H. (1998). Structure and function of a sea urchin orthodenticle-related gene (HpOtx). Dev. Biol. 193: 139-145.

KLEIN, W.H. and LI, X. (1999). Function and evolution of Otx proteins. Biochem. Biophys. Res. Comm. 258: 229-233.
LI, X., CHUANG, C.-K., MAO, C.-A., ANGERER, L.M. and KLEIN, W.H. (1997). Two Otx proteins generated from multiple transcripts of a single gene in Strongylocentrotus purpuratus. Dev. Biol. 187: 253-266.

LOWE, C.J. and WRAY, G.A. (1997). Radical alterations in the roles of homeobox genes during echinoderm evolution. Nature 389: 718-721.

LOWE, C.J., ISSEL-TARVER, L. and WRAY, G.A. (2002). Gene expression and larval evolution: changing roles of distal-less and orthodenticle in echinoderm larvae. Evol. Dev. 4: 111-123.

MITSUNAGA-NAKATSUBO, K., AKASAKA, K., SAKAMOTO, N., TAKATA, K., MATSUMURA, Y., KITAJIMA, T., KUSUNOKI, S. and SHIMADA, H. (1998). Differential expression of sea urchin Otx isoform ( $\mathrm{HpOtx}_{E}$ and $\left.\mathrm{HpOtx}_{\mathrm{L}}\right)$ mRNAs during early development. Int. J. Dev. Biol. 42: 645-651.

MORRIS, V.B. (1995). Apluteal development of the sea urchin Holopneustes purpurescens Agassiz (Echinodermata: Echinoidea: Euechinoidea). Zool. J. Linn. Soc. 114: 349-364

MORRIS, V.B. (2001). Implications of a proposed anterior-posterior bilateral body axis in echinoderms. In M. Barker (ed.), Echinoderms 2000. Balkema, Lisse, 3538

MORRIS, V.B., BRAMMALL, J., BYRNE, M. and FROMMER, M. (2002). cDNA Hox sequences $3^{\prime}$ of the homeobox isolated from the sea urchin Holopneustes purpurescens are definitive for sea urchin Hox orthologues. DNA Seq. 13: 185193.

NIELSEN, C. (1999). Origin of the chordate central nervous system - and the origin of chordates. Dev. Genes Evol. 209: 198-205.

NIELSEN, M.G., POPODI, E., MINSUK, S. and RAFF, R.A. (2003). Evolutionary convergence in Otx expression in the pentameral adult rudiment in directdeveloping sea urchins. Dev. Genes Evol. 213: 73-82.

PETERSON, K.J., ARENAS-MENA, C. and DAVIDSON, E.H. (2000). The A/P axis in echinoderm ontogeny and evolution: evidence from fossils and molecules. Evol. Dev. 2: 93-101.

SAKAMOTO, N., AKASAKA, K., MITSUNAGA-NAKATSUBO, K., TAKATA, K. NISHITANI, T. and SHIMADA, H. (1997). Two isoforms of orthodenticle-related proteins (HpOtx) bind to the enhancer element of sea urchin arylsulfatase gene. Dev. Biol. 181: 284-295.

SIMEONE, A., ACAMPORA, D., GULISANO, M., STORNAIUOLO, A. and BONCINELLI, E. (1992). Nested expression domains of four homeobox genes in developing rostral brain. Nature 358: 687-90.

VON UBISCH, L. (1913). Die Entwicklung von Strongylocentrotus lividus. (Echinus microtuberculatus, Arbacia pustulosa.). Zeit. f. wiss. Zool. 106: 409-448.

Received: July 2003

Reviewed by Referees: July 2003

Modified by Authors and Accepted for Publication: September 2003 